\title{
Synergistic action of histamine and adenosine triphosphate on the response to noradrenaline in rabbit pulmonary artery smooth muscle cells
}

\section{R. M. Helliwell, Q. Wang, R. C. Hogg, W. A. Large}

Department of Pharmacology and Clinical Pharmacology, St. George's Hospital Medical School, Cranmer Terrace, London SW17 ORE, UK

Due to an unfortunate error a mistake occurred in the legend to Fig. 6 of the above article. The correct version should read as follows:

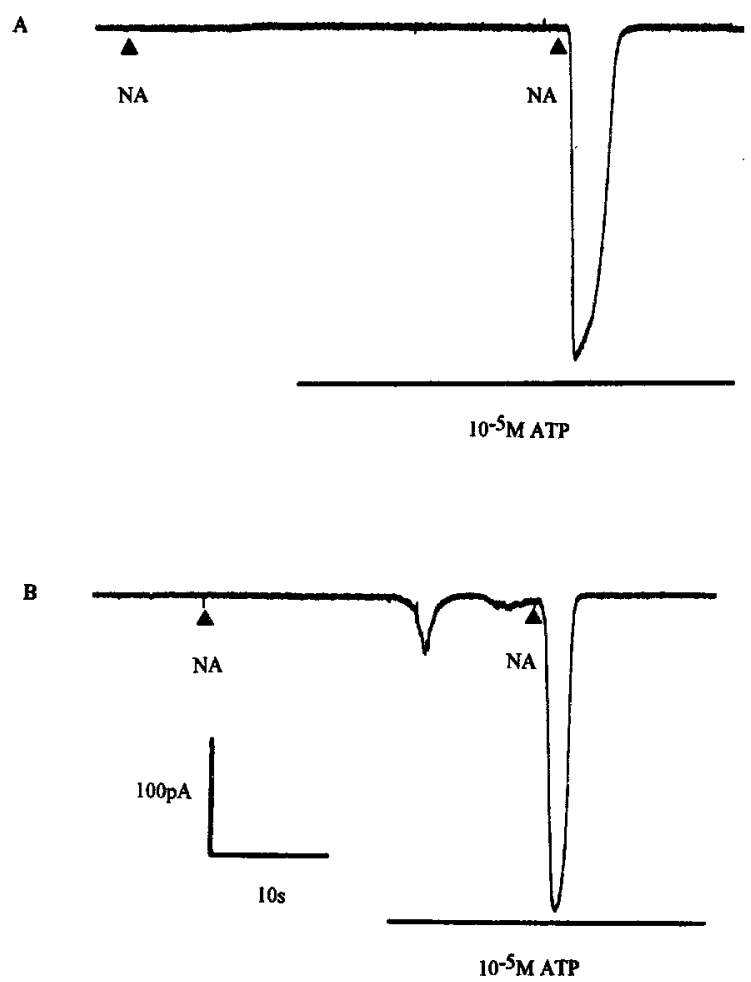

Fig. 6A, B. Potentiation by ATP of the noradrenaline-induced $I_{\mathrm{Cl}(\mathrm{Ca})} . \mathrm{K}^{+}$-free conditions; the holding potential was $-50 \mathrm{mV}$. ATP was included in the bathing solution as indicated by the horizontal bar. Ionophoretic pulse of noradrenaline (NA): $50 \mathrm{nA}$ for $1 \mathrm{~s}$ in $\mathbf{A}$ and $600 \mathrm{~ms}$ in B 